2006 ERSD Annual Report

DOE-BER Environmental Remediation Sciences Project \#86748

\title{
Microscopic Controls on the Desorption/Dissolution of Sorbed U(VI) and Their Influence on Reactive Transport
}

\author{
PIs: John M. Zachara ${ }^{1}$ \\ Co-PIs: Gordon E. Brown ${ }^{2}$, James A. Davis ${ }^{3}$, Peter C. Lichtner ${ }^{4}$, and C. I. Steefel ${ }^{5}$ \\ ${ }^{1}$ Pacific Northwest National Laboratory, Richland, WA \\ 2Stanford University, Stanford, CA \\ ${ }^{3}$ US Geological Survey, Menlo Park, CA \\ ${ }^{4}$ Los Alamos National Laboratory, Los Alamos, NM \\ ${ }^{5}$ Lawrence Berkeley National Laboratory, Berkeley, CA
}

\section{Research Objectives:}

A sizable groundwater U plume exists in Hanford's 300 A resulting from the disposal of fuel rod dissolution wastes containing $\mathrm{Al}, \mathrm{Cu}$, and $\mathrm{U}$ to the vadose zone. This project is studying $\mathrm{U}-$ contaminated samples collected along a flow path from the waste source to the Columbia River. Three primary objectives are being pursued:

- To develop microscopic models for U desorption/adsorption in sediments along the flow path including both geochemical reaction and diffusive mass transport processes.

- To parameterize the microscopic models with appropriate laboratory measurements and data within context of a dual continuum, reactive transport model (DCM).

- To apply the parameterized DCM to laboratory columns of different size and sediment texture for testing of scaling hypotheses.

\section{Research Progress and Implications:}

Molecular speciation measurements on sediments collected by excavation (Figure 1) using X-ray absorption (XAS - XANES and EXAFS) and cryogenic laser induced fluorescence spectroscopy (CLIFS) have shown that the chemical speciation of U(VI) changes from precipitated forms in the upper vadose zone near the historic source term to adsorption complexes in the deeper vadoze zone and aquifer sediments (Bond et al., 2006; Catalano et al., 2006; Wang et al., 2005, Arai et al., 2006). Precipitated U(VI) exists within secondary mineral coatings on mm-sized lithic fragments in the form of coprecipitates with calcite, and as discrete uranyl phases including metatorbernite $\left[\mathrm{Cu}\left(\mathrm{UO}_{2} \mathrm{PO}_{4}\right)_{2} \cdot 8 \mathrm{H}_{2} \mathrm{O}\right]$ and autunite. Adsorption occurs within aggregates of fine-grained phyllosilicates that include chlorite, vermiculite, and smectite, with variable ferrihydrite in low concentration. Adsorption is dominated by surface complexes to phyllosilicates in some locations and depths, and by surface complexes to ferrihydrite in others. Adsorption is significant within the fines fraction (e.g., $\log \mathrm{K}_{\mathrm{d}} \approx 0.5$ to $2.5 \mathrm{~L} / \mathrm{kg}$ ), but its overall effect is diluted strongly by mass-dominant gravel.

A critical aspect of U(VI) desorption/sorption in 300 Area sediments is that it is strongly mass transfer limited at the pore scale [Qafoku et al., (2005); and other papers in preparation]. Contaminant $U$ is released from the sediments slowly, requiring long contact times and/or repeated pore volumes of leaching to accomplish significant $U$ removal, regardless of speciation. The pore scale mass transfer process is best described with a distributed rate model. In preliminary studies comparing the $<2 \mathrm{~mm}$ fraction with whole sediments from the same location, 
we have observed that adsorption reactions scale with texture (e.g., decrease in proportion to the mass content of fines), while mass transfer properties do not (e.g., they are slower than expected; Figure 2). The rate distribution of uranium mass transfer in 300 Area sediment is a function of reactive grain size distribution and is, consequently, scale-dependent.

In comparing different sediments from the 300 Area, mass transfer rates were observed to vary with $\mathrm{U}$ molecular speciation, sediment texture, and aqueous $\mathrm{pH} /$ carbonate content. For sediments containing adsorbed U(VI), the mass transfer rate decreases with increasing sorption strength and ferrihydrite content. Desorption is invariably slower than adsorption. These findings indicate that pore scale mass transfer rates will exhibit significant heterogeneity in the field depending on sediment properties and whether desorption or adsorption is occurring. Pore scale mass transfer is thought to result from diffusive transport within particle coatings and phyllosilicate aggregates of limited porosity.

In the deeper vadose zone and groundwater where adsorption is the primary retardation process, sorption strength is found to vary strongly with groundwater geochemical composition (e.g., $\mathrm{pH}$ and carbonate content) and mineral properties of the fines fraction, such as sediment surface area, ferrihydrite content, and phyllosilicate distribution (Bond et al., 2006).

Accordingly, the distribution coefficient $\left(\mathrm{K}_{\mathrm{d}}\right)$ varies by two orders of magnitude (Figure 3 ), over the range in water composition and sediment characteristics present at the site. A surface complexation model (SCM) has been developed for the 300 Area sediments (Bond et al., 2006) that explicitly includes aqueous speciation effects through surface complexation reactions:

$$
\begin{aligned}
& \mathrm{SOH}+\mathrm{UO}_{2}{ }^{2+}+\mathrm{H}_{2} \mathrm{O}=\mathrm{SOUO}_{2} \mathrm{OH}+2 \mathrm{H}^{+} \\
& \mathrm{SOH}+\mathrm{UO}_{2}{ }^{2+}+\mathrm{H}_{2} \mathrm{CO}_{3}=\mathrm{SOUO}_{2} \mathrm{CO}_{3}+2 \mathrm{H}^{+}
\end{aligned}
$$

Where SOH is an undifferentiated surface site with concentration of $3.84 \mu \mathrm{mole} / \mathrm{m}^{2}$. This model semi-quantitatively describes carbonate and $\mathrm{pH}$ effects on U(VI) adsorption and allows semiquantitative prediction of $\mathrm{K}_{\mathrm{d}}$. However, different surface-area normalized, SCM model parameters are required for each sediment indicating the presence of uncharacterized variability in sediment mineralogy or site concentration.

\section{Planned Activities:}

Research over the next two years of project performance will address the following issues:

- Mineralogic and physical causes for mass-transfer controlled desorption/sorption, and the specific sediment properties that control rates.

- Characterization and measurement of microscopic transport parameters (e.g., diffusivity and tortuosity) and physical characteristics (e.g., porosity and thickness) of U-sorption domains.

- Parameterization of the DCM and application to column adsorption/desorption experiments of different sizes with different sediment textures.

\section{Information Access:}

\section{Publications}

Catalano, J. G., S. M. Heald, J. M. Zachara, and G. E. Brown, Jr. 2004. Spectroscopic and diffraction study of uranium speciation in contaminated vadose zone sediments from the Hanford site, Washington State, USA. Environ. Sci. Technol. 38:2822-2828. 
Liu, C., J. M. Zachara, O. Qafoku, J. P. McKinley, and S. M. Heald. 2004. Dissolution of uranyl microprecipitates in subsurface sediments at Hanford Site, USA. Geochim. Cosmochim. Acta 68(22):4519-4537.

Wang, Z., J. M. Zachara, W. Yantasee, P. L. Gassman, C. Liu, and A. G. Joly. 2004. Cryogenic laser induced fluorescence characterization of U(VI) in Hanford Vadose Zone pore waters. Environ. Sci. Technol. 38(21):5591-5597.

Wang, Z., J. M. Zachara, W. Yantasee, P. L. Gassman, C. Liu, and A. G. Joly. 2004. Cryogenic laser induced fluorescence characterization of U(VI) in Hanford Vadose Zone pore waters. Environ. Sci. Technol. 38(21):5591-5597.

Qafoku, N. P., Zachara, J. M., Liu, C., Gassman, P. L., Qafoku, O., and Smith, S. C., 2005. Kinetic desorption and sorption of $\mathrm{U}(\mathrm{V})$ during reactive transport in a contaminated Hanford sediment. Environ Sci Technol 39, 3157-3165.

Wang, Z., Zachara, J. M., McKinley, J. P., Smith, S. C., and Heald, S. M., 2005. Cryogenic laser induced $\mathrm{U}(\mathrm{VI})$ fluorescence studies of a $\mathrm{U}(\mathrm{VI})$ substituted natural calcite: Implications to U(VI) speciation in contaminated Hanford sediments. Environ. Sci. Technol. 39, 2651-2659.

Wang, Z., J. M. Zachara, P. L. Gassman, O. Qafoku, and J. Catalano. 2005. Fluorescence spectroscopy of U(VI)-silicates and U(VI)-contaminated Hanford sediment. Geochimica et Cosmochimica Acta 69(6): 1391-1403.

Arai, Y; Marcus, M.A.; Tamura, N.; Davis, J.A.; and Zachara, J.M. 2006. Spectroscopic evidence of uranium bearing precipitates in vadose zone sediments at the Hanford 300-Area Site. Environ. Sci. Technol.(Submitted).

Bond, D. L., Davis, J. A., and Zachara, J. M., 2006. Uranium(VI) dissolution and desorption from contaminated vadose zone sediments, Hanford 300-Area, Washington. Geochim. Cosmochim. Acta (Submitted).

Catalano, J. G., McKinley, J. P., Zachara, J. M., Smith, S. C., and Brown, G. E., Jr., 2006. Changes in uranium speciation through a depth sequence of contaminated Hanford sediments. Environ. Sci. Technol. 40, 2517-2524.

Fox, P. A., J. A. Davis, and J. M. Zachara. 2006. The effect of calcium on aqueous uranium(VI) speciation and adsorption to ferrihydrite and quartz. Geochim. Cosmochim. Acta 70(6):13791387.

Ilton, E. S., C. Liu, W. Yantasee, Z. Wang, D. Moore, and J. M. Zachara. 2006. The dissolution of synthetic Na-boltwoodite in sodium carbonate solutions. Geochim. Cosmochim. Acta 70:4836-4849.

Liu, C., J. M. Zachara, W. Yantasee, P. D. Majors, and J. P. McKinley. 2006. Microscopic reactive diffusion of uranium in contaminated sediments from Hanford, USA: Characterization and modeling. Water Resources Research (Submitted). 
McKinley, J. P., J. M. Zachara, C. Liu, S. M. Heald, B. I. Prenitzer, and B. W. Kempshall. 2006. Microscale controls on the fate of contaminant uranium in the vadose zone, Hanford Site, Washington. Geochim. Cosmochim. Acta, 70(8):1873-1887.

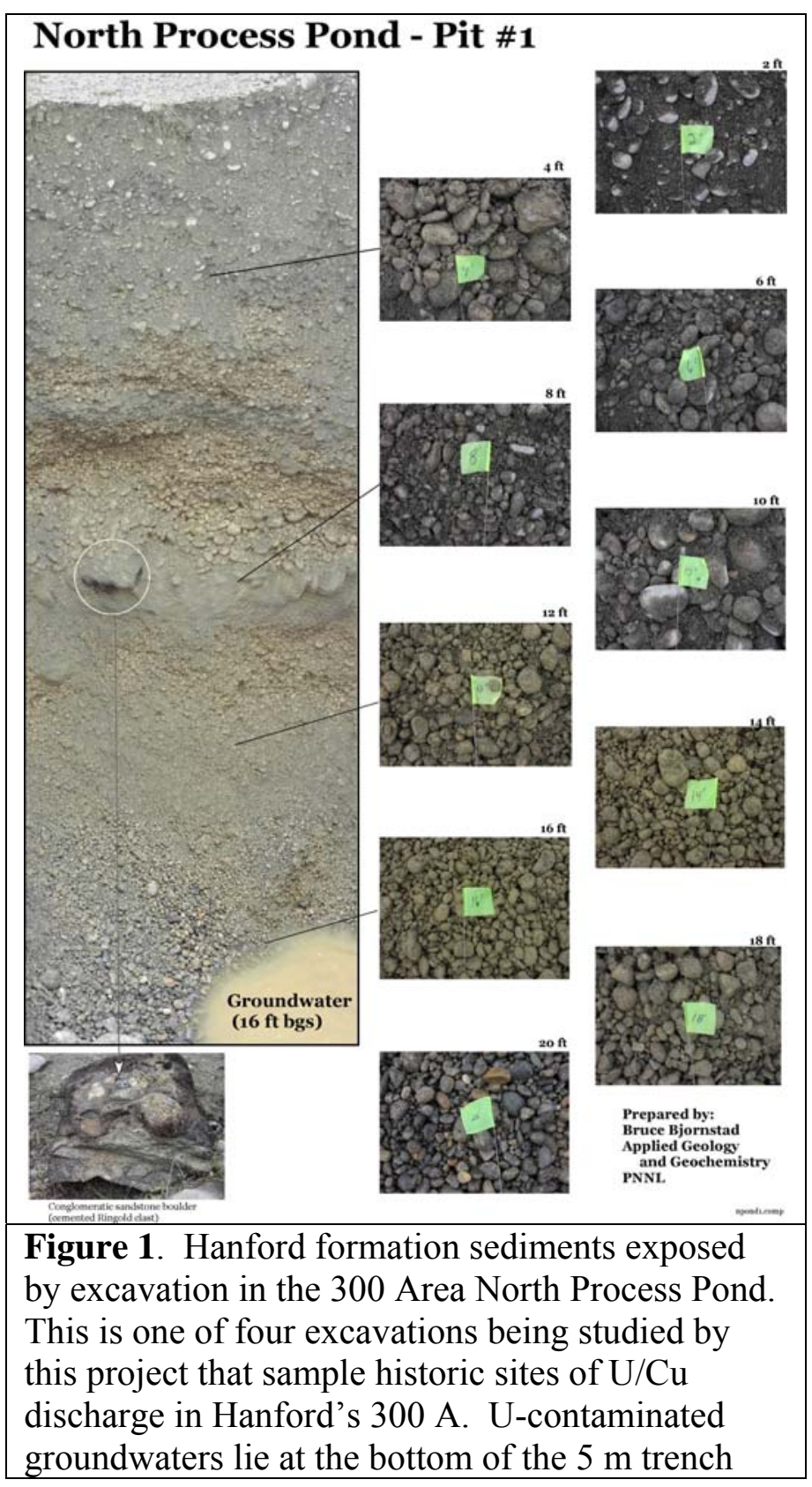



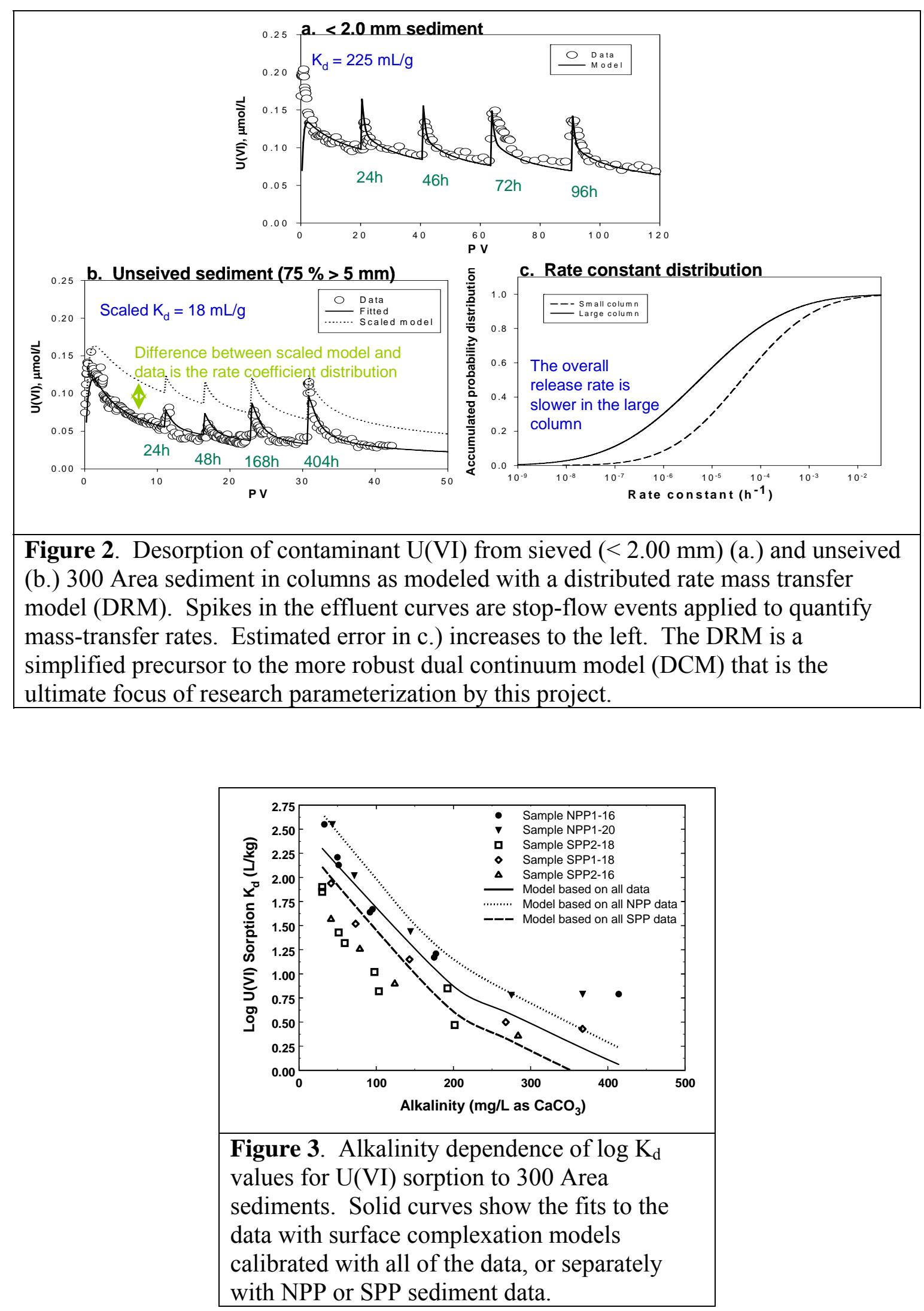